\title{
Prevalence of Geriatric Depression and Associated Factors in Kalika Rural Municipality of Rasuwa District, Nepal
}

\author{
Rajesh Karki ${ }^{1}$, Bibek Paudel ${ }^{1}$, Anil Chaudhary ${ }^{1}$, Ramesh Bhatta ${ }^{1}$, \\ Sanjaya Kumar Shah ${ }^{1}$, Josana Khanal ${ }^{1}$ \\ ${ }^{1}$ Department of Public Health, Yeti Health Science Academy, Kathmandu, Nepal \\ Corresponding Author: Rajesh Karki
}

DOI: https://doi.org/10.52403/ijhsr.20220125

\begin{abstract}
Background: Geriatric depression, which has primarily been studied in high-income nations, is anticipated to become more prevalent as the world's old population grows. In low- and middle-income nations like Nepal, similar studies are rare.

Objectives: This aimed to determine the prevalence of geriatric depression and its associated factors in 60 years and above age group of both sexes.

Setting and Design: A community based cross-sectional study was conducted in the Kalika rural municipality of Rasuwa district, Nepal.

Methods and materials: Face to face interview technique and Geriatric Depression Scale (GDS-15) was used to collect information from 305 respondents aged above 60 years which was the required sample size of the study. Simple random technique was used for the selection of respondents.

Statistical analysis used: Chi-square test at 5\% level of significance was used to identify association between socio-demographic, individual, contextual factors with geriatric depression.

Results: A total of 305 elderly people were participated in this study. The mean age was $70.91( \pm 9.165)$ years. Overall prevalence of depression was $31.1 \%$. Study also found that geriatric depression was significantly associated with living with children, family type, working status, family income, chronic illness, physical capabilities, involving in social activities, worried of being elderly, feeling of stress about life, family support, communication with family member and vital role in decision making $(\mathrm{p}<0.05)$.

Conclusion: Geriatric depression was prevalent in Kalika rural municipality. Based on these identified variables, current health programs should focus on addressing these challenges.
\end{abstract}

Keywords: Geriatric depression, community based cross-sectional study, Geriatric Depression Scale, prevalence

\section{INTRODUCTION}

The senior population is steadily increasing over the world. By 2050, the number of old people aged 60 and more is expected to double, with the greatest increases occurring in low- and middleincome (LAMI) nations and similarly, depression's prevalence is also projected to increase in alarming rate. These demographic shifts are likely to provide significant challenges for social and health care services. ${ }^{[1,2]}$ In the elderly, depression is a common cause of impairment. Reduced life satisfaction and quality, social deprivation, loneliness, greater use of health and home care services, cognitive decline, impairments in everyday tasks, suicide, and higher non-suicide mortality are some of the effects.[3] The older population is growing, and geriatric depression is becoming more 
widespread.[4] Today, over 322 million individuals worldwide suffer from depression, with nearly half of these coming from the Southeast Asian and Western Pacific regions. Depression is projected to affect $4.4 \%$ of the world's population..[5] In Nepal, depression affects 17.3 to $89.1 \%$ of elderly in nursing homes, 25.5 to 60.6 percent of elders living in the community, and 53.2 to 57.1 percent of elders in hospitals.[6] Geriatric depression is a serious public health concern that reduces quality of life and costs the family and society money.[1] Although the number of elderly people in Nepal is continually increasing, the government has given little importance to identifying their problems through research or even implementing the existing senior citizen act.[7]

\section{Objectives}

The aim of this study is to determine the prevalence of depression and its associated factors among community living elderly.

\section{MATERIALS AND METHODS Study area and design}

The current study was conducted in Kalika rural municipality of Rasuwa district, Nepal. It was descriptive cross-sectional study design with a community-based approach.

\section{Sample size determination}

Assuming a prevalence of geriatric depression (p) $56.0 \%$ which was take from the study conducted in Kavre district of Nepal.[1] The sample size was calculated by using formula $\mathrm{n}=\mathrm{Z}^{2} \mathrm{pq} / \mathrm{d}^{2}$. where $Z=1.96$ (95\% confidence interval $[\mathrm{CI}]) ; P=$ Prevalence value (Reference); $q=1-\mathrm{P} ; d=$ Margin of error which was taken as $5 \%$. The sample size came out to be 378 . According to municipal data, there are a total of $(\mathrm{N})$ 1066 persons in Kalika rural municipality who are 60 years old or older. Now, we estimated a sample size of 305 persons by using the formula $\mathrm{n}=\frac{n_{0}}{1+n o / N}[8]$, and adding a $10 \%$ non-response rate. Where $\mathrm{n}=$ sample size for finite population, $\mathrm{n} 0=$ sample size for infinite population, and $\mathrm{N}=1066$ (total population of elderly population)

\section{Sampling technique and procedure}

The voter list was collected from the Kalika Municipality office, which served as the study sampling frame. A list of people over the age of 60 was compiled. A total of 305 (n0) respondents were selected by simple random sampling i.e., Using random table.

\section{Data collection: Tools and techniques}

Face-to-face interviews were conducted using a semi-structured questionnaire to collect data on sociodemographic characteristics, as well as individual and interpersonal factors.

The depression was assessed using the Geriatric Depression Scale (GDS-15).[9] Each question was graded on a scale of 1 to 0 . Score 1 showed that the answer to the question awarded one point for depressed symptoms, while a score of 0 indicated that no point was awarded. Depression symptoms were classified as normal (0-4), mild (5-8), moderate (9-11) and severe (1215).[2] This tool had already used in Nepal.[10] Before beginning data collection, the questionnaire was developed in English, translated into Nepali, and field tested.

\section{Data collection procedure}

In order to assure the quality of research, the quality in each research process was planned. Before beginning the study, we visited the study location and obtained authorization from the concerned authorities. The Yeti Health Science Academy's Institutional Review Committee (YHSA IRC) and the Research Committee both gave their approval. Before data was collected, the purpose of the study was explained to the respondents, and written consent was acquired. Every day, the questionnaire was double-checked for accuracy and completeness. 


\section{Data analysis}

The data were entered using EpiData (version 3.1) software package, and SPSS statistical software, version 20, was used to execute all of the analyses. Data on sociodemographic characteristics, individual and contextual factors were analyzed using descriptive statistics. Chi-square test was applied for the association between geriatric depression and risk factors.

\section{RESULTS}

\section{Socio-demographic variables}

Table 1: Socio-demographic characteristics of the respondents \begin{tabular}{|l|l|l}
\hline Variables & Frequency & Percentage
\end{tabular}

\begin{tabular}{|c|c|c|}
\hline 年 & $(\mathbf{N})$ & $(\%)$ \\
\hline \multicolumn{3}{|l|}{ Age } \\
\hline $60-69$ & 156 & 51.1 \\
\hline $70-79$ & 106 & 34.8 \\
\hline $80-89$ & 31 & 10.2 \\
\hline $90-99$ & 8 & 2.6 \\
\hline $100 \&$ above & 4 & 1.3 \\
\hline \multicolumn{3}{|l|}{ Sex } \\
\hline Male & 169 & 55.4 \\
\hline Female & 136 & 44.6 \\
\hline \multicolumn{3}{|l|}{ Educational status } \\
\hline Illiterate & 205 & 67.2 \\
\hline Literate & 87 & 28.5 \\
\hline Basic level & 8 & 2.6 \\
\hline Secondary level & 3 & 1.0 \\
\hline Bachelor Level and Above & 2 & 0.7 \\
\hline \multicolumn{3}{|l|}{ Marital status } \\
\hline Unmarried & 9 & 3.0 \\
\hline Married & 219 & 71.8 \\
\hline Divorced & 3 & 1.0 \\
\hline Widow & 74 & 24.3 \\
\hline \multicolumn{3}{|l|}{ Living with children } \\
\hline Yes & 256 & 83.9 \\
\hline No & 49 & 16.1 \\
\hline \multicolumn{3}{|l|}{ Ethnicity } \\
\hline Brahmin & 163 & 53.4 \\
\hline Chhetri & 16 & 5.2 \\
\hline Janajati & 113 & 37.0 \\
\hline Dalit & 13 & 4.3 \\
\hline \multicolumn{3}{|l|}{ Religion } \\
\hline Hindu & 192 & 63.0 \\
\hline Buddhism & 105 & 34.4 \\
\hline Christian & 8 & 2.6 \\
\hline \multicolumn{3}{|l|}{ Family type } \\
\hline Nuclear & 68 & 22.3 \\
\hline Joint & 237 & 77.7 \\
\hline \multicolumn{3}{|l|}{ Working status } \\
\hline Working & 179 & 58.7 \\
\hline Not working & 126 & 41.3 \\
\hline \multicolumn{3}{|l|}{ If working (which work) } \\
\hline Agriculture & 167 & 54.8 \\
\hline Business & 12 & 3.9 \\
\hline \multicolumn{3}{|l|}{ Family income } \\
\hline $\begin{array}{l}\text { For six months, meet the most } \\
\text { basic needs }\end{array}$ & 171 & 56.1 \\
\hline $\begin{array}{l}\text { For six months, do not meet the } \\
\text { basic requirement }\end{array}$ & 134 & 43.9 \\
\hline
\end{tabular}

\section{Individual variables}

Tobacco products, alcoholic products, chronic illness, functional capabilities, death of a family member, social activities, worries of being elderly, stress, and financial requirement management are some of the individual variables included in this study.

From the table 3, it can interpret that out of 305 respondents, $166 \quad(54.4 \%)$ consumed tobacco products, while the remaining $139(45.6 \%)$ did not. Only 69 $(22.6 \%)$ of respondents consumed alcohol, while the majority of $236(77.4 \%)$ did not. When it comes to physical chronic illness, 
over half of the respondents $132(43.3 \%)$ have it, with the majority of them suffering from COPD and High Blood Pressure 56 $(42.4 \%)$ and $38(28.8 \%)$ respectively. In terms of physical abilities, the majority of the respondents $235,(77 \%)$ were capable of carrying out their everyday duties, while the remainder $70(23 \%)$ were not.

Table 2: Individual's characteristics of the respondents

\begin{tabular}{|c|c|c|}
\hline Variables & $\begin{array}{l}\text { Frequency } \\
\text { (N) }\end{array}$ & $\begin{array}{l}\text { Percentage } \\
(\%)\end{array}$ \\
\hline \multicolumn{3}{|l|}{ Consumption of tobacco } \\
\hline Yes & 166 & 54.4 \\
\hline No & 139 & 45.6 \\
\hline \multicolumn{3}{|l|}{ Consumption of alcohol } \\
\hline Yes & 69 & 22.6 \\
\hline No & 236 & 77.4 \\
\hline \multicolumn{3}{|c|}{ Presence of physical chronic illness } \\
\hline Yes & 132 & 43.3 \\
\hline No & 173 & 56.7 \\
\hline \multicolumn{3}{|l|}{ If yes, which illness $(\mathrm{n}=132)$} \\
\hline High Blood Pressure & 38 & 28.8 \\
\hline Diabetes Mellitus & 13 & 9.8 \\
\hline Cancer & 1 & .8 \\
\hline COPD & 56 & 42.4 \\
\hline Heart Disease & 9 & 6.8 \\
\hline Others & 15 & 11.4 \\
\hline \multicolumn{3}{|c|}{ Physical abilities to carry out daily tasks } \\
\hline Yes & 235 & 77.0 \\
\hline No & 70 & 23.0 \\
\hline \multicolumn{3}{|l|}{ Involvement in social activities } \\
\hline Yes & 220 & 72.1 \\
\hline No & 85 & 27.9 \\
\hline \multicolumn{3}{|l|}{ Worries of being elderly } \\
\hline Yes & 101 & 33.1 \\
\hline No & 204 & 66.9 \\
\hline \multicolumn{3}{|c|}{ If Yes, Types of worriedness $(\mathrm{n}=101)$} \\
\hline Financial Insecurity & 67 & 63.2 \\
\hline Dissatisfaction with old age & 27 & 25.5 \\
\hline Reduced interest in different ac & 4 & 3.8 \\
\hline Fear of future about exclusion $\mathrm{f}$ & 8 & 7.5 \\
\hline \multicolumn{3}{|c|}{ Death of family members within 12 months } \\
\hline Yes & 30 & 9.8 \\
\hline No & 275 & 90.2 \\
\hline \multicolumn{3}{|l|}{ Feeling of stress about Life } \\
\hline Yes & 82 & 26.9 \\
\hline No & 223 & 73.1 \\
\hline \multicolumn{3}{|c|}{ Management of financial requirements } \\
\hline Self-Working & 120 & 39.3 \\
\hline Depends upon family & 176 & 57.7 \\
\hline Social Security Allowance & 9 & 3.0 \\
\hline
\end{tabular}

In terms of social activities, the majority of respondents $220(72.1 \%)$ were involved in them, while only $85(27.9 \%)$, were not. When asked why they were worried, just $101(33.1 \%)$ said they were worried about becoming old, while financial instability was the leading reason of worriedness i.e., 67 (63.2\%). Similarly, the majority of $223(73.1 \%)$ people do not experience any stress in their lives, more than half of $176(57.7 \%)$ people rely on family members for financial support, and only $30(9.8 \%)$ people have experienced the death of a family member in the last 12 months.

\section{Contextual variables}

Contextual variables include family support, adequate communication with family members, and a critical role in family decision-making.

Table 3, shows information on the respondents' contextual characteristics. In terms of family support, the majority of respondents $256(86.9 \%)$ had family support, whereas the $40(13.1 \%)$ did not. The majority of respondents, $245(80.3 \%)$, had adequate communication with their family, while the remainder $60(19.7 \%)$ did not have adequate communication with their family member. In terms of vital involvement in family decision-making, the majority of respondents, 204 (66.9\%), said they played a critical part in family decision-making.

Table 3: Contextual characteristics of the respondents

\begin{tabular}{|l|l|l|}
\hline Variables & Frequency & Percentage (\%) \\
\hline Family support & 265 & 86.9 \\
\hline Yes & 40 & 13.1 \\
\hline No & 245 & 80.3 \\
\hline Adequate communication with family members \\
\hline Yes & 60 & 19.7 \\
\hline No & 204 & 66.9 \\
\hline Vital role in decision making in family \\
\hline Yes & 101 & 33.1 \\
\hline No &
\end{tabular}

\section{Prevalence of Geriatric depression}

Table 4: Distribution of respondents according to depression

\begin{tabular}{|l|l|l|}
\hline Variables & Frequency(N) & Percentage (\%) \\
\hline Depression & 95 & 31.1 \\
\hline Yes & 210 & 68.9 \\
\hline No & \multicolumn{2}{|l|}{} \\
\hline Level of Depression(n=210) & 210 & 68.9 \\
\hline No Depression & 73 & 23.9 \\
\hline Mild Depression & 20 & 6.6 \\
\hline Moderate Depression & 2 & 0.7 \\
\hline Severe Depression &
\end{tabular}

The total prevalence of depression in the study population was $95(31.1 \%)$, with $210(68.9 \%)$ participants having no depression, according to the Geriatric Depression Scale (GDS-15). There are 73 
Rajesh Karki et.al. Prevalence of geriatric depression and associated factors in Kalika Rural Municipality of Rasuwa District, Nepal.

(23.9\%) people who have moderate depression, $20(6.6 \%)$ who have moderate depression, and only $2(0.7 \%)$ who have no depression (Table 4).

\section{Associations of geriatric depression}

The data presented in table 5 shows statistical association of depression with living with children $(\mathrm{p}=0.002)$, family type $(\mathrm{p}=0.002)$, working status $(\mathrm{p}=0.000)$ and family income $(p=0.000)$, but sex was not associated with depression $(\mathrm{p}=0.386)$.

Table 5: Association between geriatric depression and selected demographic variables

\begin{tabular}{|c|c|c|c|}
\hline \multirow{2}{*}{$\begin{array}{l}\text { Socio-demographic } \\
\text { characteristics }\end{array}$} & \multicolumn{2}{|c|}{ Depression } & \multirow{2}{*}{$\begin{array}{l}p \text { - } \\
\text { value }\end{array}$} \\
\hline & Present & Absent & \\
\hline & $\mathbf{N}(\%)$ & $\mathbf{N}(\%)$ & \\
\hline \multicolumn{4}{|l|}{ Sex } \\
\hline Male & $49(29 \%)$ & $120(71 \%)$ & \\
\hline Female & $46(34 \%)$ & $90(66 \%)$ & \multirow[t]{2}{*}{0.386} \\
\hline \multicolumn{3}{|l|}{ Living with children } & \\
\hline Yes & $70(27 \%)$ & $186(73 \%)$ & \multirow[t]{2}{*}{0.002} \\
\hline No & $25(51 \%)$ & $24(49 \%)$ & \\
\hline \multicolumn{4}{|l|}{ Family type } \\
\hline Nuclear & $32(47 \%)$ & $36(53 \%)$ & \multirow[t]{2}{*}{0.002} \\
\hline Joint & $63(27 \%)$ & $174(73 \%)$ & \\
\hline \multicolumn{4}{|l|}{ Working status } \\
\hline Working & $35(20 \%)$ & $144(80 \%)$ & \multirow[t]{2}{*}{0.000} \\
\hline Not Working & $60(48 \%)$ & $66(52 \%)$ & \\
\hline \multicolumn{4}{|l|}{ Family income } \\
\hline $\begin{array}{l}\text { For six months, meet the most } \\
\text { basic needs }\end{array}$ & $34(20 \%)$ & $137(80 \%)$ & \multirow[t]{2}{*}{0.000} \\
\hline $\begin{array}{l}\text { For six months, do not meet } \\
\text { the basic requirement }\end{array}$ & $61(46 \%)$ & $73(54 \%)$ & \\
\hline
\end{tabular}

Table 6: Association between geriatric depression and selected individual variables

\begin{tabular}{|c|c|c|c|}
\hline \multirow[t]{2}{*}{ Variables } & \multicolumn{2}{|c|}{ Depression } & \multirow[t]{2}{*}{ p-value } \\
\hline & Present & Absent & \\
\hline & $\mathbf{N}(\%)$ & $\mathbf{N}(\%)$ & \\
\hline \multicolumn{3}{|c|}{ Consumption of tobacco } & \\
\hline Yes & $51(31 \%)$ & $115(69 \%)$ & \multirow[t]{2}{*}{0.901} \\
\hline No & $44(32 \%)$ & $95(68 \%)$ & \\
\hline \multicolumn{3}{|c|}{ Consumption of alcohol } & \\
\hline Yes & $28(40 \%)$ & $41(60 \%)$ & \multirow[t]{2}{*}{0.054} \\
\hline No & $67(28 \%)$ & $169(72 \%)$ & \\
\hline \multicolumn{3}{|c|}{ Presence of chronic illness } & \\
\hline Yes & $52(39 \%)$ & $80(61 \%)$ & \multirow[t]{2}{*}{0.007} \\
\hline No & $43(25 \%)$ & $130(75 \%)$ & \\
\hline \multicolumn{3}{|c|}{ Physical abilities to carry out daily tasks } & \\
\hline Yes & $47(20 \%)$ & $188(80 \%)$ & \multirow[t]{2}{*}{0.000} \\
\hline No & $48(69 \%)$ & $22(31 \%)$ & \\
\hline \multicolumn{3}{|c|}{ Involvement in social activities } & \multirow{3}{*}{0.000} \\
\hline Yes & $42(19 \%)$ & $178(81 \%)$ & \\
\hline No & $53(62 \%)$ & $32(38 \%)$ & \\
\hline \multicolumn{3}{|c|}{ Worries of being elderly } & \\
\hline Yes & $60(59 \%)$ & $41(41 \%)$ & \multirow[t]{2}{*}{0.000} \\
\hline No & $35(17 \%)$ & $169(83 \%)$ & \\
\hline \multicolumn{3}{|c|}{ Death of family member within 1 year } & \multirow{3}{*}{0.270} \\
\hline Yes & $12(40 \%)$ & $18(60 \%)$ & \\
\hline No & $83(30 \%)$ & $192(70 \%)$ & \\
\hline \multicolumn{3}{|c|}{ Feeling of stress about life } & \multirow{3}{*}{0.000} \\
\hline Yes & $54(66 \% 0$ & $28(34 \%)$ & \\
\hline No & $41(18 \%)$ & $182(82 \%)$ & \\
\hline
\end{tabular}

Table 6 demonstrates statistical association of geriatric depression with presence of chronic illness $(\mathrm{p}=0.007)$, physical capabilities for doing daily living activities $(\mathrm{p}=0.000)$, involvement in social activities $(\mathrm{p}=0.000)$, worriedness of being elderly $(\mathrm{p}=0.000)$ and feeling of stressful life $(\mathrm{p}=0.000)$ but consumption of tobacco $(p=0.901)$, consumption of alcohol $(\mathrm{p}=0.054)$ and death of family member within 12 months $(p=0.270)$ were not associated with depression.

Table 7 shows statistical association of depression with family support $(\mathrm{p}=0.000)$, adequate communication with family member $(p=0.000)$ and role of decision making in family $(\mathrm{p}=0.000)$.

Table 7: Association between geriatric depression and selected contextual variables

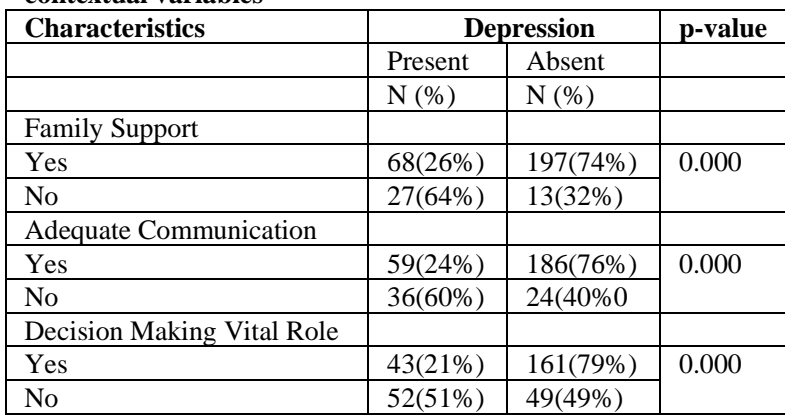

\section{DISCUSSION}

According to the current study, 31.1 $\%$ of the older population suffers from depression, which is consistent with previous findings. Chalise and Rai [7] found that $29.7 \%$ Nepalese rai older adults in the Kathmandu valley were depressed. Jadav and Patel [11] found 34.1\% depression among senior population in rural area of Vadodara, Gujrat and Pilania, Yadav [12] found $34.4 \%$ depression among Indian elderly population. However, some studies contradict our findings: a study conducted among elderly people in a rural south Indian community found $12.7 \%$ [13], a study conducted in north India $9.5 \%$ [14], a study conducted in Thailand $18.5 \%$ [15] , and a study conducted in Nepal among older adults found $15.4 \%[16]$ which is lower than my study and some were higher than our study; a study conducted by 
Shrestha, Shrestha [6] in the emergency department of teaching hospital in Nepal found $45.7 \%$ prevalence of geriatric depression, Jemal, Hailu [17] found 54.5 percent, and a study conducted by Simkhada, Wasti [18] among older adults in Kathmandu Nepal found $60.6 \%$. This variation may be due to different in study setting and tool used to assess depression.

The relationship between geriatric depression and socio-demographic, environmental, and individual characteristics was investigated in this study. And the findings suggest that sociodemographic characteristics such family type, living with children, elderly population working status, and family income are all associated to geriatric depression. Contextual characteristics such as family support, good communication among family members, and family decision-making roles were also associated to depression. However, sex and individual factors such as cigarette use, alcohol consumption, and the presence of chronic disease were not associated to geriatric depression, which is consistent with earlier findings; a study conducted by Shrestha, Shrestha [6] found an association between the presence of chronic disease and depression and no association between age and depression, John and Nath [19] found type of family associated with depression but age was not associated, Bineetha, Vijayakumar [20] found sex, alcohol and tobacco consumption were not associated with depression, but that being unemployed was, Manandhar, Risal [1] found sex, alcohol consumption were not associated with depression, but that having a chronic health problem and physical capability were. Similarly, other studies have found that family support, living with children, stress, a lack of decision-making, and family income are all strongly associate to depression $[1,2,21]$.

\section{CONCLUSION}

The findings of this study revealed that the majority of respondents $(68.9 \%)$ were normal, while the remaining 31.1 percent were depressed, implying that out of every ten respondents, three were suffering from a mental health disorder, namely depression, which is still considered a public health challenge. Factors linked to depression in the senior population should be investigated further, and relevant public health interventions should be implemented by local governments to address these issues.

\section{Acknowledgement}

The authors thank Yadav Prasad Sapkota (Chief administrative officer), Navaraj Neupane (Health coordinator) and all the research participants of Kalika rural municipality for their support and valuable time.

Ethical Approval: Ethical approval was provided by the institutional review committee of Yeti Health Science Academy (YHSA-IRC).

\section{Conflict of Interest: None}

\section{Source of Funding: None}

\section{REFERENCES}

1. Manandhar K, Risal A, Shrestha O, Manandhar N, Kunwar D, Koju R, et al. Prevalence of geriatric depression in the Kavre district, Nepal: Findings from a cross sectional community survey. BMC psychiatry. 2019;19(1):1-9.

2. Mali P, Poudel EN, Mali S, Poudel L, Joshi SP. Depression and its associated factors among elderly people of old age homes and community of Kathmandu district, Nepal: a comparative study. International Journal of Community Medicine and Public Health. 2021;8(4):1571.

3. Khattri JB. Study of depression among geriatric population in Nepal. Nepal Med Coll J. 2006;8(4):220-3.

4. Shrestha K, Ojha SP, Dhungana S, Shrestha S. Depression and its association with quality of life among elderly: An elderly home-cross sectional study. Neurology, Psychiatry and Brain Research. 2020;38:14. 
5. Naveen KHS, Goel AD, Dwivedi S, Hassan MA. Adding life to years: Role of gender and social and family engagement in geriatric depression in rural areas of Northern India. Journal of Family Medicine and Primary Care. 2020;9(2):721.

6. Shrestha R, Shrestha AP, Shrestha A, Kamholz B. Unrecognized geriatric depression in the emergency Department of a Teaching Hospital in Nepal: prevalence, contributing factors, and metric properties of 5 item geriatric depression scale in this population. BMC psychiatry. 2020;20(1):112.

7. Chalise H, Rai S. Prevalence and correlates of depression among Nepalese Rai older adults. Journal of Gerontology \& Geriatric Research. 2013;2(4):1-5.

8. Dahal M, Dhakal S, Khanal S, Baral K, Mahaseth S. Linkage of Depression with Elder Abuse among Institutionalized Older Persons in Kathmandu Valley, Nepal. Psychiatry journal. 2021;2021.

9. Greenberg SA. The geriatric depression scale (GDS). Best Practices in Nursing Care to Older Adults. 2012;4(1):1-2.

10. Sharma KR, Yadav BK, Battachan M. Correlates of depression among elderly population residing in a community in Eastern Nepal. Birat Journal of Health Sciences. 2018;3(1):325-30.

11. Jadav P, Patel MV. Prevalence of depression and factors associated with it in geriatric population in rural area of Vadodara, Gujarat. IJCMPH. 2017; 4(12).

12. Pilania M, Yadav V, Bairwa M, Behera P, Gupta SD, Khurana H, et al. Prevalence of depression among the elderly (60 years and above) population in India, 1997-2016: a systematic review and meta-analysis. BMC public health. 2019;19(1):1-18.

13. Rajkumar A, Thangadurai $P$, Senthilkumar P, Gayathri K, Prince M, Jacob K. Nature, prevalence and factors associated with depression among the elderly in a rural south Indian community. International psychogeriatrics. 2009;21(2):372-8.

14. Sharma K, Gupta A, Sharma RC, Mahajan N, Mahajan A, Sharma D, et al. Prevalence and risk factors for depression in elderly
North Indians. Journal of Geriatric Mental Health. 2016;3(2):158.

15. Mitsiriswat A. The prevalence and associated factors influencing depression in the geriatric population: A cross-sectional study in Ban Nayao, Chachoengsao Province, Thailand. Revue d'Épidémiologie et de Santé Publique. 2018;66:S278.

16. Thapa DK, Visentin DC, Kornhaber R, Cleary M. Prevalence and factors associated with depression, anxiety, and stress symptoms among older adults: A cross-sectional population-based study. Nursing \& Health Sciences. 2020; 22(4): 1139-52.

17. Jemal K, Hailu D, Tesfa B, Lama T, Kinati $\mathrm{T}$, Mengistu E. Geriatric depression and quality of life in North Shoa Zone, Oromia region: a community cross-sectional study. Annals of General Psychiatry. 2021;20(1):110.

18. Simkhada R, Wasti SP, Gc VS, Lee AC. Prevalence of depressive symptoms and its associated factors in older adults: a crosssectional study in Kathmandu, Nepal. Aging \& mental health. 2018;22(6):802-7.

19. John J, Nath KR. Prevalence and factors associated to depression among geriatric population in a rural area of Kanyakumari district Tamil Nadu. International journal of community medicine and public health (Gujarat). 2019;6(2):804-7.

20. Bineetha B, Vijayakumar P, Senan SK, Paul G. A Study of the Prevalence of Depression in Geriatric Outpatients and Associated Predisposing Factors. International Journal of Medical Science and Clinical Invention. 2018;5(01):3454-9.

21. Bhamani MA, Karim MS, Khan MM. Depression in the elderly in Karachi, Pakistan: a cross sectional study. BMC psychiatry. 2013;13(1):1-8.

How to cite this article: Karki R, Paudel B, Chaudhary A et.al. Prevalence of geriatric depression and associated factors in Kalika Rural Municipality of Rasuwa District, Nepal. Int J Health Sci Res. 2022; 12(1): 188-194. DOI: https://doi.org/10.52403/ijhsr.20220125 